\title{
EFEITO DA PELETIZAÇÃO E ADIÇÃO DE ENZIMAS E VITAMINAS SOBRE O DESEMPENHO EAPROVEITAMENTO DA ENERGIA E NUTRIENTES EM FRANGOS DE CORTE DE 1 A 21 DIAS DE IDADE
}

\author{
Effect of pelleting and addition of enzymes and vitamins on the performance and advantage of \\ energy and nutrients in broiler chickens from 1 to 21 days old
}

\author{
José Laureano Barbosa Leite ${ }^{1}$, Paulo Borges Rodrigues ${ }^{2}$, Elias Tadeu Fialho ${ }^{3}$, \\ Rilke Tadeu Fonseca de Freitas ${ }^{2}$, Adriano Kaneo Nagata $^{4}$, Vinícius de Souza Cantarelli ${ }^{5}$
}

\begin{abstract}
RESUMO
Conduziu-se este experimento para avaliar o efeito da peletização e adição de enzimas e vitaminas sobre o desempenho e aproveitamento da energia e nutrientes, em frangos de corte de 1 a 21 dias de idade. Foram utilizados 350 pintos de corte, COBB, machos, com peso inicial médio de $47 \mathrm{~g} \pm 2,5 \mathrm{~g}$, em um delineamento inteiramente casualizado, com os tratamentos em arranjos fatorial 3 x 2 (três dietas, com e sem enzimas) sendo que as dietas consistiram de uma ração farelada e duas rações peletizadas,uma com adição de vitaminas e minerais após a peletização e a outra com adição de vitaminas e minerais antes da peletização. O tempo e a temperatura da peletizadora variaram de 05 a 09 minutos e $58^{\circ} \mathrm{C}$ a $62^{\circ} \mathrm{C}$, respectivamente. Após esse processo, as rações peletizadas foram trituradas, buscando-se manter a mesma granulometria das rações fareladas. $\mathrm{O}$ ensaio de desempenho foi realizado com 10 repetições e o de metabolismo com 5 repetições cada tratamento, em uma densidade de 5 aves por parcela (gaiola). As rações foram formuladas com $95 \%$ das recomendações nutricionais e fornecidas às aves com uma restrição alimentar de, aproximadamente, $10 \%$ do consumo ad libitum, o qual foi calculado diariamente a partir do consumo médio de um grupo de aves controle, que foram submetidas ao consumo à vontade de uma ração formulada para atender $100 \%$ dos níveis nutricionais recomendados. O complexo enzimático utilizado foi o Allzyme Vegproß, contendo em sua composição as enzimas protease, amilase e celulase, adicionado aos tratamentos seguindo as recomendações do fabricante, de $0,5 \mathrm{~kg}$ por tonelada de ração. Aos 21 dias de idade avaliou-se o ganho de peso e a conversão alimentar. Também foram coletadas as excretas, pela metodologia de coleta total de excretas, nos dias 20,21 e 22 , para determinação dos valores energéticos das rações e digestibilidade da gordura e da proteína. Pelos resultados obtidos, observou-se que o ganho de peso, a conversão alimentar, a energia metabolizável aparente corrigida e o coeficiente de digestibilidade do extrato etéreo apresentaram interação significativa $(\mathrm{P}<0,01)$, entre dieta e enzimas, onde a dieta peletizada com enzima e com adição de vitaminas e minerais, antes da peletização, apresentaram melhor desempenho. Quanto ao coeficiente de digestibilidade da proteína bruta (CDPB), não houve interação ( $\mathrm{P}>0,05)$ entre dieta e enzima. Houve efeito significativo $(\mathrm{P}<0,05)$ das dietas sobre CDPB e diferença significativa $(\mathrm{P}<0,05)$ em relação à adição de enzimas sobre as dietas. Conclui-se que as dietas peletizadas com adição de vitaminas e minerais, antes do processo de peletização, promoveu efeito no desempenho das aves, refletindo positivamente no ganho de peso, na conversão alimentar e nos coeficientes de digestibilidade da proteína bruta, do extrato etéreo e da energia metabolizável aparente corrigida das aves.
\end{abstract}

Termos para indexação: Aves, aditivos, coeficientes de digestibilidade e forma física.

\section{ABSTRACT}

It was carried out an experiment to evaluate the effect of pelleting and addition of enzymes and vitamins on the performance and advantage of energy and nutrients in broiler chickens from 1 to 21 days old. A total of 350 broiler chickens, COBB, males, were used $((47 \mathrm{~g} \pm 2.5 \mathrm{~g})$ in a completely randomized design, with the treatments in a $3 \times 2$ factorial arrangement (three diets with or without enzymes) and (two diets based on corn and soybean one meal two pelleted, with or without addition of vitamins and minerals after pelleting and the other with addition of vitamins and minerals before pelleting. The time and temperature of pelleting ranged from 5 to 9 minutes and $58^{\circ} \mathrm{C}$ to $62^{\circ} \mathrm{C}$, respectively. After this process, the pelleted rations were ground with the same particle size similar to meal rations. In the performance assay were utilized 10 replicates and the of metabolism assay it was with 5 replicates in each treatment with density of 5 chickens per plot (cage). The diets were formulated with $95 \%$ of the nutritional recommendations and the chickens were fed with in a feed restriction of $10 \%$ from ad libitum intake, which was calculated daily from the average intake of a group of chickens control, which were submitted to ad libitum intake of a diet formulated with $100 \%$ of the nutritional levels

\footnotetext{
${ }^{1}$ Mestre - Departamento de Desenvolvimento Educacional/DDE - Escola Agrotécnica Federal de Colatina/EAFCOL - Rodovia Br 259 , Km 70 - Zona Rural - 29709-910 - Colatina, ES - jlbleite@yahoo.com.br

${ }^{2}$ Zootecnistas, Doutores, Professores - Departamento de Zootecnia/DZO - Universidade Federal de Lavras/UFLA - Cx. P. 3037 - $37200-000$ - Lavras, MG pborges@ufla.br; rilke@ufla.br

${ }^{3}$ Engenheiro Agrônomo, Ph. D. - Departamento de Zootecnia/DZO - Universidade Federal de Lavras/UFLA - Cx. P. 3037 - $37200-000$ - Lavras, MG fialho@ufla.br

${ }^{4}$ Zootecnista, Doutor - Assistente Técnico Comercial/Avicultura - Tortuga Companhia Zootécnica Agrária - Rua Araguari, 358, Sala 803, 18a andar Barro Preto - 30190-110 - Belo Horizonte, MG - adriano.nagata@tortuga.com.br

5Zootecnista, Doutor - Departamento de Zootecnia/DZO - Universidade Federal de Lavras/UFLA - Cx. P. 3037 - $37200-000$ - Lavras, MG viniciuscantarelli@yahoo.com.br
} 
recommended. The enzyme complex utilized was Allzyme Vegpro®, containing the enzymes protease, amylase and cellulase, which were added to the treatments following the manufacturer's recommendations, of $0.5 \mathrm{~kg}$ per ton of ration. At final of 21 days old, weight gain and feed conversion were evaluated. The excreta were collected by the methodology of total collection in the 20,21 and 22 days to determination of the energetics values of the diets and as well as the ether extract and protein digestibility coefficients. The weight gain, feed conversion, corrected apparent metabolizable energy and coefficient of digestibility of ether extract showed a significant interaction $(\mathrm{P}<0.01)$ between diets and enzymes, where the pelleted diet with enzyme and with addition of vitamins and minerals before pelleting presented better performance. Thee coefficient of digestibility of crude protein (CDCP), there was no interaction $(\mathrm{P}>0.05)$ between diet and enzyme. There was a significant effect $(\mathrm{P}<0.05)$ of the diets on CDCP. There was a significant difference $(\mathrm{P}<0.05)$ in relation to the addition of enzymes in the diets. It was concluded that in pelleted rations with addition of vitamins and minerals before pelleting process, showed better chickens performance as well as better coefficients of digestibility of crude protein, ether extract and corrected apparent metabolizable energy of rations of broiler chickens from 1 to 21 days old.

Index terms: Broiler chickens, additive, metabolism assay .

\section{(Recebido em 31 de julho de 2006 e aprovado em 6 de junho de 2007)}

\section{INTRODUÇÃO}

Os constantes avanços tecnológicos obtidos e a utilização de aves com grande potencial genético direcionado para o crescimento e demais índices zootécnicos de interesse, a avicultura brasileira apresenta alta eficiência e volume de produção. No entanto, sabe-se que os nutrientes dos alimentos presentes nas rações normalmente utilizadas para aves não são completamente utilizados, pois contêm substâncias indisponíveis para as enzimas endógenas, como por exemplo, os polissacarídeos não amiláceos (PNAs). Nesse contexto, as enzimas exógenas têm sido incorporadas às rações dos animais com o propósito de melhorar a utilização dos nutrientes pouco disponíveis, proporcionando melhor desempenho das aves e, com isso, a rentabilidade no sistema de produção.

Existem, todavia, alguns fatores limitantes na adição de enzimas para aves. As condições de processamento das rações, como temperatura, umidade, tempo, vapor e pressão podem comprometer a ação das enzimas na dieta dos animais (FRANCESCH, 1996).

Brito et al. (2006), em experimento, avaliaram a adição de um complexo enzimático (amilase, protease e celulase) em dietas à base de soja extrusada sobre o desempenho de pintos de corte. Os autores observaram que a adição do complexo enzimático melhorou o $\operatorname{GP}(3,8 \%)$ e a C.A $(4,24 \%)$ das aves.

Souza (2005), trabalhando com complexo enzimático em rações fareladas e peletizadas, para frangos de corte, observou que a adição de enzimas, em ração farelada à base de milho e farelo de soja melhora o desempenho das aves e melhora a energia metabolizável verdadeira das rações. Observou, ainda, que a utilização de complexo enzimático em rações peletizadas é influenciada pela desnaturação enzimática decorrente das temperaturas utilizadas no processo.
Porém, existe uma dúvida se o processo de peletização pode afetar a utilização de enzimas na dieta, e mesmo das vitaminas fornecidas pelos concentrados vitamínicos. Conduziu-se, o presente trabalho, com o objetivo de avaliar o efeito da peletização e adição de enzimas e vitaminas, sobre o desempenho e aproveitamento da energia e nutrientes, em frangos de corte de 1 a 21 dias de idade.

\section{MATERIAL E MÉTODOS}

O experimento foi conduzido na sala de metabolismo do Setor de Avicultura do Departamento de Zootecnia da Universidade Federal de Lavras-MG.

Foram utilizados 350 pintos de corte, Cobb, machos, vacinados contra doença de Marek e Bouba Aviária e com peso médio inicial de $47 \mathrm{~g} \pm 2,5 \mathrm{~g}$. As aves, em número de 5, foram alojadas em gaiolas de arame galvanizado, com dimensões de $50 \mathrm{~cm}$ x $50 \mathrm{~cm}$ x $50 \mathrm{~cm}$, dotadas de um comedouro tipo calha e um bebedouro tipo copo de pressão.

Utilizou-se o delineamento experimental inteiramente casualizado, com os tratamentos em arranjos fatorial $3 \times 2$ (três dietas, com e sem enzimas), realizando-se simultaneamente, o desempenho com 10 repetições e o metabolismo com 5 repetições seguindo o mesmo delineamento, em uma densidade de 5 aves por parcela (gaiola), perfazendo um total de 60 parcelas. As dietas consistiram de uma ração farelada e duas rações peletizadas, sendo uma com adição de vitaminas e minerais após a peletização e a outra com adição de vitaminas e minerais antes da peletização, que foram formuladas com e sem adição de complexo enzimático, para atender $95 \%$ das recomendações de Rostagno (2000). As rações foram fornecidas às aves com uma restrição alimentar de, aproximadamente, $10 \%$ do consumo ad libitum, o qual foi calculado diariamente a partir do consumo médio de um 
grupo de aves- controle, que consumiram à vontade uma ração formulada para atender a $100 \%$ dos níveis nutricionais recomendados por Rostagno (2000). Este procedimento foi feito para calcular a ração a ser fornecida aos tratamentos que receberam restrição.

O complexo enzimático (Allzyme Vegpro·) composto de amilase, protease e celulase foi adicionado aos tratamentos seguindo as recomendações do fabricante, de $0,5 \mathrm{~kg}$ do complexo enzimático por tonelada de ração.

As rações peletizadas foram preparadas pelo processo de mistura convencional e peletizadas usandose uma peletizadora industrial (Marca CPM 2000), com peneira de 4,0 $\mathrm{mm}(3 / 32)$ e com temperatura interna e tempo da peletizadora variando entre $58^{\circ} \mathrm{C}$ a $62^{\circ} \mathrm{C}$ e de 05 a 09 minutos, respectivamente. As rações peletizadas foram trituradas para manter a mesma granulometria das rações fareladas e acrescentado vitaminas e minerais naquelas em que esses nutrientes não foram adicionados antes da peletizacão.

O consumo de ração das aves foi controlado diariamente, pela diferença entre o peso de ração fornecida e a sobra no comedouro no dia seguinte, em todas as parcelas experimentais do grupo controle, cujo distribuição de ração foi ad libitum, seguindo as recomendações do manual da linhagem Cobb 500. Os valores determinados em cada repetição do grupo-controle obteve-se a média e, com ela, fez-se a restrição de aproximadamente $10 \%$, obtendo-se a quantia de ração a ser distribuída para as aves dos tratamentos experimentais.

O ganho de peso foi determinado, por meio da pesagem do grupo de animais de cada parcela, pela diferença entre o seu peso inicial e o peso aos 21 dias.

A conversão alimentar foi calculada utilizando-se o consumo de ração e o ganho de peso das unidades experimentais.

Para determinar a energia metabolizável aparente corrigida, coeficiente de digestibilidade do extrato etéreo e da proteína bruta, foram coletadas as excretas das aves no período final da fase experimental ( 20 a 22 dias de idade). Foi utilizado o método de coleta total das excretas, sendo essa realizada uma vez ao dia, durante o período de três dias, sendo esse período considerado suficiente, segundo Rodrigues et al. (2005).

Durante o período de coleta, as excretas foram acondicionadas em sacos plásticos, identificados e armazenados em freezer até o período final de coleta, quando foram pesadas, descongeladas à temperatura ambiente, homogeneizadas e delas retiradas alíquotas de $350 \mathrm{~g}$ para análises, passando por uma pré-secagem em estufa de ventilação forçada a $55^{\circ} \mathrm{C}$, durante 72 horas.
Após a pré-secagem, as amostras foram processadas em moinho tipo faca, com peneira de $1 \mathrm{~mm}$ e acondicionadas em potes plásticos, identificadas e encaminhadas ao Laboratório de Pesquisa Animal do DZO/UFLA, junto com amostras das rações experimentais, para determinação, em triplicatas, da matéria seca (MS), nitrogênio $(\mathrm{N})$, extrato etéreo (EE) e energia bruta (EB), que foi determinada em bomba calorimétrica adiabática (PARR - Modelo 1261), seguindo a metodologia descrita por (SILVA, 2002).

As composições porcentual e nutritiva das rações experimentais encontram-se na Tabela 1.

Com base nos resultados laboratoriais obtidos, foram calculados a EMAn, por meio das fórmulas descritas por Matterson et al. (1965) e os CDEE e CDPB.

Os resultados de CR, GP, CA, EMAn, CDPB e CDEE foram submetidos a análises de variância, utilizando o pacote computacional Sistemas para Análises de Variância (SISVAR), segundo Ferreira (2000).Os tratamentos foram comparados pelo teste de médias Student-Newman-Keuls, a $5 \%$ de probabilidade.

\section{RESULTADOS E DISCUSSÕES}

Na Tabela 2, encontram-se os valores médios do ganho de peso (GP) e conversão alimentar (CA) das aves, no período de 1 a 21dias de idade.

Não foi observada interação significativa $(\mathrm{P}>0,05)$ entre as dietas e enzimas nem efeito significativo $(\mathrm{P}>0,05)$ das dietas sobre o consumo de ração, visto que o mesmo foi restrito, atendendo-se, então, aos objetivos propostos.

Apesar da restrição no consumo, aplicada em todos tratamentos experimentais, observa-se que os resultados do presente trabalho corroboram com aqueles obtidos por Fischer et al. (2002), que também não observaram diferença no consumo quando adicionaram enzimas em rações fareladas. Entretanto, Garcia et al. (2000) verificaram maior consumo de ração em frangos de corte, tanto em dietas fareladas quanto peletizadas, à base de milho e soja, quando foram suplementadas com as mesmas enzimas, cabendo ressaltar novamente que esses autores não trabalharam com restrição alimentar, o que foi feito no presente experimento.

Resultados semelhantes também foram encontrados por Brum \& Coldebella (2005) que observaram aumento de consumo de ração e do ganho de peso sem afetar a conversão alimentar e retenção de energia, embora esses autores não tenham trabalhado com restrição alimentar. 
Tabela 1 -Composição porcentual das rações experimentais utilizadas. ${ }^{1}$

\begin{tabular}{|c|c|c|}
\hline Ingredientes & Sem enzima & Com enzima \\
\hline Milho & 60,00 & 60,00 \\
\hline Farelo de soja & 33,40 & 33,40 \\
\hline Óleo de soja & 1,00 & 1,00 \\
\hline Fosfato bicálcico & 1,72 & 1,72 \\
\hline Calcário calcítico & 0,90 & 0,90 \\
\hline Sal comum & 0,40 & 0,40 \\
\hline Premix mineral $^{2}$ & 0,10 & 0,10 \\
\hline Premix vitamínico ${ }^{3}$ & 0,10 & 0,10 \\
\hline DL-metionina $99 \%$ & 0,18 & 0,18 \\
\hline L-lisina-HCl & 0,10 & 0,10 \\
\hline Cloreto de colina $60 \%$ & 0,05 & 0,05 \\
\hline Anticoccidiano $^{4}$ & 0,05 & 0,05 \\
\hline Inerte (caulim) & 2,00 & 1,95 \\
\hline Enzima & 0,00 & 0,05 \\
\hline Total & $100 \mathrm{~kg}$ & $100 \mathrm{~kg}$ \\
\hline \multicolumn{3}{|c|}{ Composição nutritiva calculada das rações experimentais. } \\
\hline Nutrientes & Rostagno (2000) & $95 \%$ recomendações \\
\hline Energia metabolizável, kcal/kg & 3000 & 2850 \\
\hline Proteína bruta, $\%$ & 21,40 & 20,33 \\
\hline Cálcio, \% & 0,96 & 0,91 \\
\hline Fósforo disponível, \% & 0,45 & 0,42 \\
\hline Sódio, \% & 0,22 & 0,21 \\
\hline Metionina + cistina, $\%$ & 0,897 & 0,85 \\
\hline Lisina, $\%$ & 1,263 & 1,20 \\
\hline Treonina, \% & 0,795 & 0,76 \\
\hline Triptofano, $\%$ & 0,21 & 0,19 \\
\hline
\end{tabular}

${ }^{1}$ Calculado de acordo com a composição química e níveis nutricionais recomendados por Rostagno (2000).

${ }^{2}$ Premix mineral: níveis de garantia, por kg do produto:cálcio $10.150 \mathrm{mg}$; cobre $20.000 \mathrm{mg}$; ferro $50.000 \mathrm{mg}$; iodo $2400 \mathrm{mg}$; manganês $170.000 \mathrm{mg}$; zinco $100.000 \mathrm{mg}$; selênio $1.000 \mathrm{mg}$;

${ }^{3}$ Premix vitamínico: níveis de garantia, por kg do produto: vitamina A 32.000 UI; vitamina D3 6.000 UI; vitamina E $60.000 \mathrm{mg}$; vitamina k3 8.000mg; vitamina B1 5.000mg; vitamina B2 20.000mg; vitamina B6 7.500mg; vitamina B12 $60.000 \mathrm{mg}$; ácido pantotênico $40.000 \mathrm{mg}$; niacina $120.000 \mathrm{mg}$; ácido fólico $2.500 \mathrm{mg}$; biotina $400.000 \mathrm{mg}$; antioxidante $125.000 \mathrm{mg}$.

${ }^{4}$ Anticoccidiano: Salinomicina $12 \%$

Os resultados observados para o ganho de peso dos frangos de corte no período de 1 a 21 dias de idade encontram-se na Tabela 2 , mostrando interação significativa $(\mathrm{P}<0,01)$ entre as dietas e a adição de enzimas e havendo efeito significativo $(\mathrm{P}<0,01)$ das dietas sobre ganho de peso e diferença significativa $(\mathrm{P}<0,05)$ das enzimas sobre o ganho de peso.

Fazendo-se uma comparação entre a adição ou não de enzimas, para cada dieta, verifica-se que o uso do complexo enzimático influenciou $(\mathrm{P}<0,05)$ o ganho de peso das aves, podendo-se observar melhor desempenho das aves que receberam a ração farelada com enzimas e a ração peletizada com enzima, com adição de vitaminas e minerais, antes da peletização.

Os resultados referentes ao grupo-controle foram, para o consumo médio de ração $1.205 \mathrm{~g}$ (60), o ganho de peso de $672 \mathrm{~g}$ (32) e a conversão alimentar de $1,79 \mathrm{~g} / \mathrm{g}(0,11)$, formulada para atender a $100 \%$ dos níveis nutricionais recomendados por Rostagno (2000). 
Tabela 2 - Desempenho, de 1 a 21 dias de idade, de frangos de corte, alimentados com dietas farelada e peletizada, adicionadas ou não com enzimas e com adição de vitaminas e minerais antes e após a peletização e seus respectivos desvios padrões.

\begin{tabular}{|c|c|c|c|c|c|c|}
\hline \multicolumn{6}{|c|}{1 a 21 dias } & \\
\hline \multirow[t]{2}{*}{ Dietas $^{1}$} & \multicolumn{2}{|c|}{ Ganho de peso $(\mathrm{g})^{1,2^{*}}$} & \multicolumn{4}{|c|}{ Conversão alimentar (g/g) } \\
\hline & Com enzima & Sem enzima & Média & Com enzima & Sem enzima & Média \\
\hline 1 & 593 (14) Aa & $574(13) \mathrm{Bb}$ & 584 & $1,73(0,04) \mathrm{Aa}$ & $1,79(0,02) \mathrm{Bb}$ & 1,76 \\
\hline 2 & $566(10) \mathrm{Ba}$ & $573(09) \mathrm{Ba}$ & 570 & $1,81(0,03) \mathrm{Bb}$ & $1,79(0,04) \mathrm{Bb}$ & 1,80 \\
\hline 3 & 583 (10) Aa & $573(09) \mathrm{Bb}$ & 578 & $1,76(0,03) \mathrm{Aa}$ & $1,80(0,01) \mathrm{Bb}$ & 1,77 \\
\hline Média & 580 & 573 & & 1,76 & 1,79 & \\
\hline $\mathrm{CV} \%$ & & 1,95 & & & 1,98 & \\
\hline
\end{tabular}

${ }^{1}$ Dieta farelada sem enzima; farelada com enzima; 2- peletizada sem enzima com adição de vitaminas e minerais após a peletização; peletizada com enzima com adição de vitaminas e minerais após a peletização; 3- peletizada sem enzima com adição de vitaminas e minerais antes da peletização; peletizada com enzima com adição de vitaminas e minerais antes da peletização.

${ }^{1 *}$ Médias com letras maiúsculas distintas na mesma coluna indicam diferenças significativas $(\mathrm{P}<0,05)$, pelo teste de médias Student-Newman-Keuls.

${ }^{2 *}$ Médias com letras minúsculas distintas na mesma linha indicam diferenças significativas $(\mathrm{P}<0,05)$, pelo teste $\mathrm{F}$.

Observou-se que o ganho de peso foi melhorado em 3,31\% quando se utilizou a ração farelada com enzimas e, no caso das rações peletizadas com adição de enzimas e de vitaminas e minerais antes da peletização, observaram-se melhoras no ganho de peso de $1,78 \%$ em relação às dietas não suplementadas, evidenciando o efeito positivo das enzimas quando adicionadas às rações dos animais.

Os resultados de conversão alimentar dos frangos de corte apresentaram interação significativa $(\mathrm{P}<0,01)$ entre as dietas e a adição de enzimas. Houve efeito significativo $(\mathrm{P}<0,01)$ das dietas sobre a conversão alimentar e diferença significativa $(\mathrm{P}<0,05)$ das enzimas sobre a conversão alimentar. Os dados indicaram melhora na conversão alimentar nas rações fareladas com enzimas de $2,81 \%$ e, nas peletizadas com enzimas com adição de vitaminas e minerais antes da peletização, melhora de $1,68 \%$.

Os valores médios da energia metabolizável aparente corrigida pelo nitrogênio retido (EMAn), coeficiente de digestibilidade do extrato etéreo (CDEE) e da proteína bruta (CDPB) das rações experimentais são apresentados na Tabela 3 .

Resultados referentes ao grupo controle foram para EMAn 3.121kcal/kg (35), o CDEE de 79,6\% (0,7) e CDPB de $79,1 \%(2,1)$.

Pelos valores de EMAn determinados observase que houve interação significativa $(\mathrm{P}<0,01)$ entre as dietas e a adição de enzimas e efeito significativo
$(\mathrm{P}<0,01)$ das dietas sobre a EMAn e diferença significativa $(\mathrm{P}<0,01)$ das enzimas sobre a EMAn. Verifica-se um aumento significativo na EMAn das aves que receberam a ração farelada com enzimas, representando $6,58 \%$ de melhora no valor energético em comparação às aves que receberam a ração farelada sem enzimas. Também as aves que receberam rações peletizadas com enzimas e com adição de vitaminas e minerais antes da peletização apresentaram melhora de $4,46 \%$, em relação àquelas que receberam as rações não suplementadas, evidenciando a eficácia do uso do complexo enzimático e a adição de vitaminas e minerais antes da peletização. Por meio da ação conjunta das enzimas, pode ter havido uma diminuição da viscosidade da digesta com aumento da absorção dos nutrientes da ração.

Estabelecendo-se uma comparação entre a adição de enzimas, para as dietas 1 e 3, constata-se que a EMAn para as aves que consumiram as rações que continham enzimas foi superior às demais rações, evidenciando que a inclusão da enzima foi eficiente em melhorar a EMAn, exceção para a dieta 2 .

Esses resultados estão de acordo com os encontrados por Zanella \& Sakomura (1999), que, trabalhando com enzimas, obteve diferença significativa nos valores da EMAn de frangos intactos. Os referidos autores observaram um acréscimo que variou de $1,09 \%$ a $2,77 \%$, resultando em um aumento médio de $1,93 \%$. 
Carvalho (2006) também observou um acréscimo que variou de $2,01 \%$ a $4,36 \%$ da EMAn, em um experimento com frangos de corte, testando complexos enzimáticos em rações fareladas. Porém, no presente trabalho, o aumento foi de $6,58 \%$ nas rações fareladas com enzimas e de $4,46 \%$ quando utilizou-se as rações peletizadas com enzimas e com adição de vitaminas e minerais antes da peletização, portanto superior àquelas encontradas pelo referido autor.

Souza (2005), trabalhando com um complexo enzimático em rações fareladas e peletizadas para frangos de corte, observou que a EMA do milho e do farelo de soja podem ser valoradas em $2 \%$ e $9 \%$, respectivamente, sem afetar o desempenho das aves.

Houve interação significativa $(\mathrm{P}<0,01)$ entre as dietas e a adição de enzimas e efeito significativo $(\mathrm{P}<0,01)$ das dietas sobre o CDEE. Houve diferença significativa $(\mathrm{P}<0,01)$ das enzimas sobre o CDEE. Para as aves que receberam as rações fareladas com enzimas, houve um aumento de $10,11 \%$ no CDEE, e para as que receberam rações peletizadas com enzimas, com adição de vitaminas e minerais antes da peletização, houve aumento de $6,61 \%$ em relação às dietas não suplementadas.

$\mathrm{O}$ CDEE apresentou efeito significativo $(\mathrm{P}<0,01) \mathrm{com}$ a suplementação enzimática adicionada às rações, corroborando com Schang (1996). Esse autor observou maior teor de gordura em frangos, demonstrando a capacidade das enzimas em melhorar a digestibilidade da energia. A utilização de enzimas proporciona melhora na digestibilidade dos nutrientes e no valor nutritivo das dietas formuladas com milho e farelo de soja, resultando em melhor desempenho de frangos de corte.

Não foi observada interação significativa $(\mathrm{P}>0,05)$ entre as dietas e a adição de enzimas no CDPB. Houve efeito significativo $(\mathrm{P}<0,05)$ da dieta sobre o CDPB e diferença significativa $(\mathrm{P}<0,01)$ das enzimas sobre o CDPB. Nas aves que receberam as rações fareladas com enzimas, o aumento foi de $7,68 \%$ e nas que receberam rações peletizadas com enzimas com adição de vitaminas e minerais antes da peletização, o aumento foi de $7,15 \%$ em relação às dietas não suplementadas.

Estabelecendo-se uma comparação entre a adição de enzimas, para as dietas 1 e 3, constata-se que CDEE e $\mathrm{CDPB}$, para as aves que consumiram as rações que continham enzimas, foram superiores às demais rações, sendo que a inclusão da enzima foi eficiente em melhorar a CDEE e CDPB, nesse experimento.

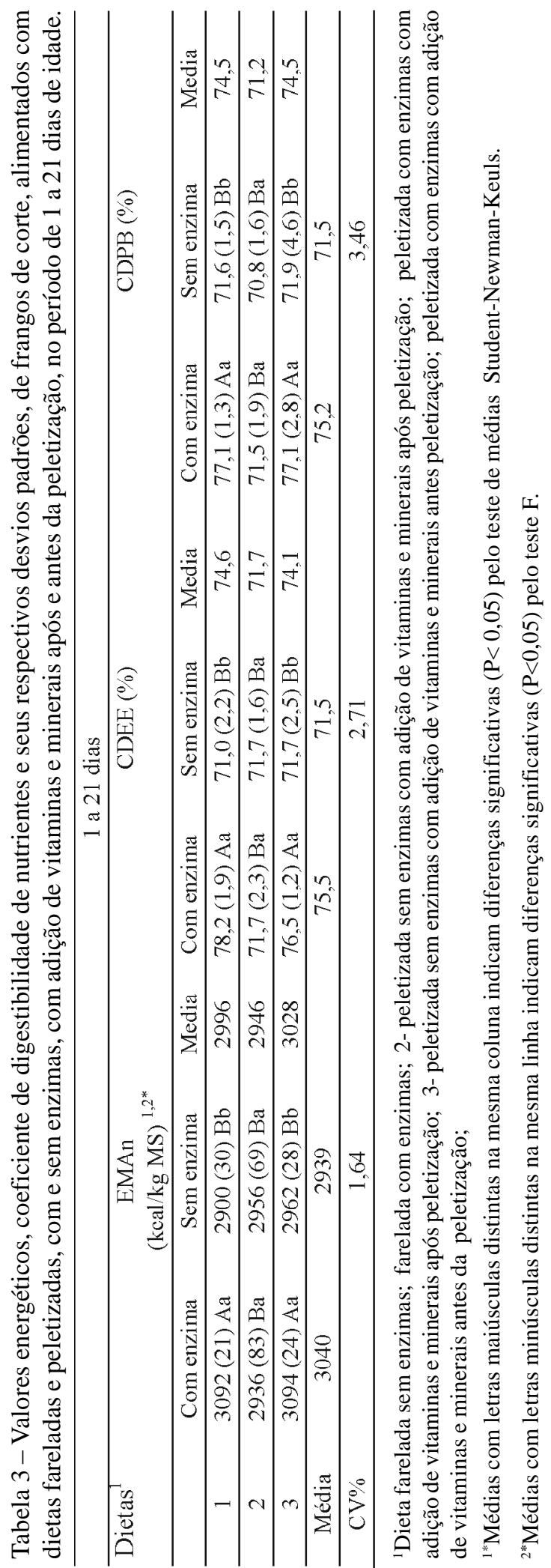

Ciênc. agrotec., Lavras, v. 32, n. 4, p. 1292-1298, jul./ago., 2008 


\section{CONCLUSÕES}

O processo de peletização das rações utilizando enzimas, vitaminas e minerais antes da peletização promoveu melhorias no desempenho das aves, refletindo positivamente no ganho de peso, na conversão alimentar e nos coeficientes de digestibilidade da proteína bruta, extrato etéreo e energia metabolizável aparente corrigida das aves.

\section{AGRADECIMENTOS}

À Alltech Agroindústria do Brasil Ltda, pelo financiamento do trabalho e à Total Alimentos S. A, pelo processamento das rações.

\section{REFERÊNCIAS BIBLIOGRÁFICAS}

BRITO, C. O.; ALBINO, L. F. T.; ROSTAGNO, H. S. Adição de complexo enzimático em dietas à base de soja extrusada e desempenho de pintos de corte. Revista Brasileira de Zootecnia, Viçosa, v. 35, n. 2, p. 457-461, 2006.

BRUM, P. A. R.; COLDEBELLA, A. Efeito da suplementação de enzimas em dietas à base de milho e farelo de soja sobre os valores de energia metabolizável e o desempenho de frangos de corte. Concórdia: [s.n.], 2005. (Comunicado técnico).

CARVALHO, J. C. C. Complexos enzimáticos em rações fareladas para frangos de corte. 2006. 64 p. Dissertação (Mestrado em Zootecnia) - Universidade Federal de Lavras, Lavras, 2006.

FERREIRA, D. F. Sistema de análise de variância de dados balanceados: pacote computacional. Lavras: DEX-UFLA, 2000.

FISCHER, G.; MAIER, J. C.; RUTZ, F.; BERMUDEZ, V. L. Desempenho de frangos de corte alimentados com dietas à base de milho e farelo de soja, com ou sem adição de enzimas. Revista Brasileira de Zootecnia, Viçosa, v. 31, n. 1, p. 402-410, 2002. Suplemento.

FRANCESCH, M. Bases de la utilización de complejos enzimáticos en avicultura. In: CURSO DE
ESPECIALIZACIÓN, 12., 1996, Madrid. Anais... Madrid: FEDNA, 1996. p. 20-32.

GARCIA, E. R. M.; MURAKAMI, A. E.; BRANCO, A. F. Efeito da suplementação enzimática em rações com farelo de soja e soja integral extrusada sobre a digestibilidade de nutrientes, o fluxo de nutrientes na digesta ileal e o desempenho de frangos. Revista Brasileira de Zootecnia, Viçosa, v. 29, n. 5, p. 1414-1426, 2000.

MATTERSON, L. D.; POTTER, L. M.; STUTZ, M. W. The metabolizable energy of feed ingredients for chickens: research report. Agricultural Experiment Station, Connecticut, v. 7, p. 3-11, 1965.

RODRIGUES, P. B. et al. Influência do tempo de coleta e metodologias sobre a digestibilidade e o valor energético de rações para aves. Revista Brasileira de Zootecnia, Viçosa, v. 34, n. 3, p. 882-889, 2005.

ROSTAGNO, H. S. (Coord.). Composição de alimentos e exigências nutricionais de aves e suínos: tabelas brasileiras. Viçosa: UFV, 2000. 141 p.

SCHANG, M. J. O uso da enzima Vegpro em dietas para frangos em crescimento. In: RONDA LATINO AMERICANA DE BIOTECNOLOGIA, 6., 1996, Curitiba. Anais... Curitiba: Alltech, 1996. p. 71-77.

SILVA, D. J. Análise de alimentos: métodos químicos e biológicos. 3. ed. Viçosa: UFV, 2002. 165 p.

SOUZA, R. M. Uso de complexo enzimático em rações fareladas e peletizadas para frangos de corte. 2005.59 p. Dissertação (Mestrado em Zootecnia) - Universidade Federal de Lavras, Lavras, 2005.

ZANELLA, I.; SAKOMURA, N. K. Effect of enzyme supplementation of broiler diets based on corn and soybeans. Poultry Science, Champaign, v. 78, n. 4, p. 561568, Apr. 1999.15 